\title{
Neutralitätsverletzungen in der Besteuerung von Kapitaleinkommen und deren Wachstumswirkungen
}

Eine theoretische und empirische Analyse des deutschen Steuersystems

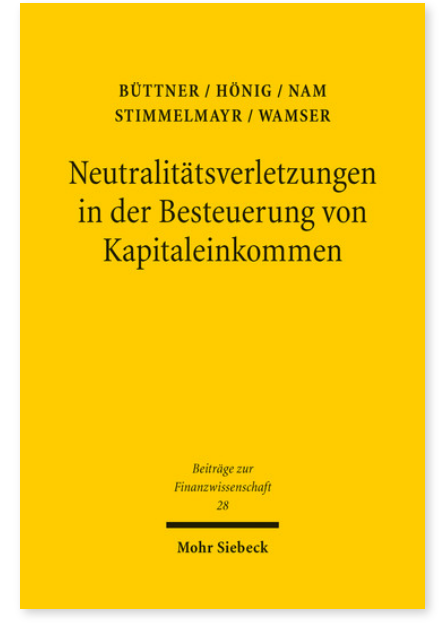

2012. XIII, 184 Seiten. BtrFin 28

ISBN 978-3-16-152092-1

DOI 10.1628/978-3-16-152092-1

eBook PDF 74,00€

ISBN 978-3-16-151832-4

fadengeheftete Broschur $74,00 €$
Auf der Grundlage einer systematischen Analyse der Besteuerung von Kapitaleinkommen wird die Entwicklung zentraler Parameter des deutschen Steuersystems unter Berücksichtigung der beiden großen Unternehmenssteuerreformen 2001 und 2008 nachvollzogen. Die Effekte der daraus resultierenden steuerlichen Verzerrungen werden anhand von Alternativszenarien quantifiziert, welche die Steuerreformen sowie die hypothetische Einführung eines optimalen Steuersystems abbilden. Die Simulationsergebnisse verdeutlichen das erhebliche Potenzial für wachstumsfördernde Steuerreformen in Deutschland.

Thiess Büttner Born 1966; studied Economics in Göttingen and Konstanz; Dr.rer.pol University of Konstanz; 2004-10 Professor of Economics at the University of Munich; since 2010 Professor of Economics at the University of ErlangenNuremberg.

Anja Hönig Geboren 1983 ; Studium der Int. VWL in Tübingen; 2008-2010 tätig als Doktorandin am ifo Institut für Wirtschaftsforschung; seit 2010 wissenschaftliche Mitarbeiterin am Lehrstuhl für VWL, insbesondere Finanzwissenschaft an der Universität Erlangen-Nürnberg.

Chang W. Nam Keine aktuellen Daten verfügbar.

Michael Stimmelmayr Geboren 1978; Studium der VWL in München; 2006 Promotion an der Universität München bei HansWerner Sinn; seit 2006 Assistenzprofessur am Center for Economic Studies (CES) an der Universität München.

Georg Wamser Geboren 1977; Studium der VWL in München; 2005-2009 tätig als Doktorand am ifo Institut für Wirtschaftsforschung; 2009 Promotion an der Universität München bei Thiess Büttner; seit 2010 Oberassistent an der ETH Zürich.

Jetzt bestellen:

https://mohrsiebeck.com/buch/neutralitaetsverletzungen-in-der-besteuerung-von-kapitaleinkommen-und-derenwachstumswirkungen-9783161520921?no cache=1

order@mohrsiebeck.com

Telefon: $+49(0) 7071-923-17$

Telefax: $+49(0) 7071-51104$ 